\title{
VALIDATION OF THE BRAZILIAN VERSION OF THE BERG BALANCE SCALE FOR PATIENTS WITH PARKINSON'S DISEASE
}

\author{
Paula L. Scalzo', Isabella C. Nova², Mônica R. Perracini', Daniel R.C. Sacramento", \\ Francisco Cardoso ${ }^{4}$, Henrique B. Ferraz ${ }^{5}$, Antonio Lúcio Teixeira ${ }^{6}$
}

\begin{abstract}
Background: Changes in balance occur with the progression of Parkinson's disease (PD). Objective: To validate the Brazilian version of the Berg Balance Scale (BBS) for PD patients, determining its reliability and internal consistency and correlating it with PD-specific instruments. Method: We evaluated 53 patients (M/F $37 / 16$, mean age $\pm S D, 62 \pm 7.9$ years) with PD (mean $\pm S D, 7.8 \pm 4.4$ years). Unified Parkinson's Disease Rating Scale (UPDRS), Schwab and England Scale (S\&E), Hoehn and Yahr Staging Scale (HY) and BBS were used to assess patients. Statistical analyses for inter-rater reliability, internal consistency and correlations among BBS, UPDRS, S\&E and HY were performed. Results: The mean scores \pm SD on UPDRS and BBS were, respectively, 41.6 \pm 17.8 and $47.2 \pm 8.2$. The median on S\&E and HY scales were $80 \%$ and 2.5 , respectively. The BBS presented a high intraclass correlation coefficient (ICC $=0.84$ ) and internal consistency (Cronbrach's $\alpha=0.92$ ). There was a statistically significant correlation between BBS and disease duration $\left(r_{s}=-0.520, p<0.001\right)$, UPDRS subscales II and III ( $r_{s}=$ $-0.467, p=0.011 ; r_{s}=-0.374, p=0.046$, respectively), stage of disease ( $\left.H Y ; r_{s}=-0.507, p<0.001\right)$ and the activities of daily living ( $S \& E ; r_{s}=0.492, p<0.001$ ). Conclusion: The BBS is a promising tool for the assessment of balance in PD, correlating with the stage of disease and the level of independence.
\end{abstract}

KEY WORDS: Parkinson's disease, postural instability, Berg Balance Scale.

\section{Validação da versão brasileira da Escala de Equilíbrio de Berg para pacientes com a doença de Parkinson}

Resumo - Alterações de equilibrio ocorrem com a progressão da doença de Parkinson (DP). Objetivo: Validar a versão brasileira da Escala de Equilíbrio de Berg (EEB) para pacientes com DP, determinando a confiabilidade, a consistência interna e correlacionando com instrumentos específicos da DP. Método: Foram avaliados 53 pacientes (H/M 37/16, idade média $\pm D P, 62 \pm 7,9$ anos) com DP (media $\pm D P, 7,8 \pm 4,4$ anos). Escala de Graduação Unificada da Doença de Parkinson (UPDRS), Escala de Schwab e England (S\&E), Escala de Estágios de Hoehn e Yahr (HY) e EEB foram utilizadas. Análise estatística para confiabilidade entre examinadores, consistência interna e correlações entre EEB, UPDRS, S\&E e HY foram realizadas. Resultados: Os escores médios $\pm D P$ nas escalas UPDRS

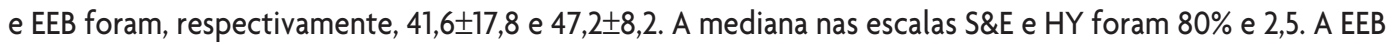
mostrou ter alto coeficiente de correlação intraclasse (ICC $=0,84$ ) e consistência interna ( $\alpha$ de Cronbach $=0,92$ ). Houve correlação estatisticamente significativa entre EEB e a duração da doença $\left(r_{s}=-0,520, p<0,001\right)$, subescalas II e III do UPDRS ( $r_{s}=-0,467, p=0,011 ; r_{s}=-0,374, p=0,046$, respectivamente), estágio da doença (HY; $r_{s}=$ $-0,507, p<0,001)$, com as atividades da vida diária ( $\left.S \& E ; r_{s}=0,492 ; p<0,001\right)$. Conclusão: A EEB é um instrumento promissor para avaliar o equilibrio na DP, correlacionando-se com o estágio da doença e o nivel de independência.

PALAVRAS-CHAVE: doença de Parkinson, instabilidade postural, Escala de Equilibrio de Berg.

\footnotetext{
Neuropsychiatric Branch and Movement Disorders Clinic, Neurology Unit, University Hospital, Federal University of Minas Gerais (UFMG), Belo Horizonte MG, Brazil and Movement Disorders Clinic, Federal University of Sao Paulo, São Paulo SP, Brazil: 'Physical Therapist, Pontifical Catholic University of Minas Gerais (PUC Minas, Betim) and Estácio de Sá University, Belo Horizonte MG, Brazil; ²Physical Therapist, Federal University of São Paulo, São Paulo SP, Brazil; ${ }^{3}$ Neurologist, University Hospital, Federal University of Minas Gerais, Belo Horizonte MG, Brazil; ${ }^{4}$ Neurologist. Department of Internal Medicine, School of Medicine, Federal University of Minas Gerais, Belo Horizonte MG, Brazil; ${ }^{5}$ Neurologist, Department of Neurology, Federal University of São Paulo, São Paulo SP, Brazil; ${ }^{6}$ Neurologist and Psychiatrist, Department of Internal Medicine, School of Medicine, Federal University of Minas Gerais, Belo Horizonte MG, Brazil. This work was supported by Rede Instituto Brasileiro de Neurociência (IBN Net/Finep), Conselho Nacional de Desenvolvimento Científico e Tecnológico (CNPq) and Fundação de Amparo à P esquisa do Estado de Minas Gerais (Fapemig), Brazil.
}

Received 19 March 2009, received in final form 8 July 2009. Accepted 30 July 2009.

Dr. Antonio Lucio Teixeira - Departamento de Clínica Médica / Faculdade de Medicina da UFMG - Av. Alfredo Balena 190 - 30130-100 Belo Horizonte MG - Brasil. E-mail: altexr@gmail.com 
Parkinson's disease (PD) is the most common neurodegenerative movement disorder, affecting $0.3 \%$ of the general population'. Pathologically, it is characterized by the progressive and irreversible loss of the dopaminergic neurons from substantia nigra pars compacta (SNpc). Clinically, PD is characterized by motor dysfunctions, including bradykinesia, resting tremor and rigidity. Postural instability occurs with the progress of the disease, and subsequently it causes falls in patients, which in turn restricts mobility, functional independence and social participation ${ }^{2-5}$. Once balance deteriorates in PD, it is important to have a quantifiable tool that health care professionals can use to monitor these changes. The Berg Balance Scale (BBS) has been the main instrument used to identify and to evaluate balance impairment in different populations, although this scale was originally designed to assess the risk of falling in elderly patients ${ }^{6-9}$. The BBS is a 14-item scale that measures static and dynamic standing balance ${ }^{6,7}$. Each item is scored on a five-point ordinal scale ranging from 0 (unable to perform) to 4 (normal performance). The total score range is 0 to 56 and higher scores denote better balance. Scores of 0 to 20 refer to those patients restricted to a wheelchair; 21 to 40 refer to assistance during the gait and 41 to 56 points correspond to independence.

Psychometric properties of this scale have been examined by various researchers. These studies showed strong internal consistency and inter- and intra-rater reliability in neurological diseases, such as stroke and $\mathrm{PD}^{8,10}$. Nova et al. demonstrated that the BSS had enough sensitivity to detect balance changes during on-off fluctuation in PD patients on levodopa therapy". Recently, Qutubuddin et al. validated the English version of the BBS for PD after evaluating 38 male patients ${ }^{12}$. BBS scores showed significant correlations with PD-specific instruments that measure motor functioning, stage of disease and daily living capacity. These researchers proposed that the BBS may be used for screening and ongoing assessment for PD. Franchignoni et al. proposed to determine unidimensionality, internal construct validity and the rating scale for PD patients ${ }^{13}$.

The aim of the present study was to assess the clinimetric properties of the Brazilian version of the BBS in patients with idiopathic PD. For this purpose, we assessed inter-rater reliability and internal consistency, and correlated BBS with PD-specific instruments.

\section{METHOD}

Demographic and clinical data were collected from $53 \mathrm{pa}-$ tients with PD from the Movement Disorders Clinic of the Federal University of Minas Gerais (UFMG) and the Movement Disorders Clinic of the Federal University of São Paulo (UNIFESP). Local ethics committees approved the study and all participants provided written consent prior to data collection.
Eligibility for the study was determined by the presence of a clinical diagnosis of PD and findings of up to stage 3 on the Modified Hoehn and Yahr Staging Scale (HY). Participants were included if they were able to stand and walk independently without the use of an assistive device. Participants were excluded if they had another neurological disease or orthopedic impairment.

Demographic and clinical assessments were completed on the same day. All patients were assessed after the use of levopoda, i.e. at "on" period. The Brazilian version of the Mini Mental State Examination (MMSE) was used to assess cognitive function $^{14}$. The PD-specific instruments used were: Unified Parkinson's Disease Rating Scale (UPDRS), Modified Hoehn and Yahr Staging Scale and Modified Schwab and England Capacity for Daily Living Scale (S\&E). These instruments were applied by an experienced neurologist. The UPDRS is currently the most widely accepted scale for measuring the different components of PD. It has 3 subscales: UPDRS I - mentation, behavior and mood (range 0-16); UPDRS II - activities of daily living (ADL) (range 0-52) and UPDRS III - motor examination (range 0-108). Each item is scored on a scale from 0 to 4 . A total of 176 points is possible with 176 representing maximal (or total) disability and 0 representing no disability ${ }^{15-17}$. The HY classifies PD patients in five stages according to body distribution of symptoms and dependency. Patients in stage I are mildly affected, while in stage $V$ they are bedrid$\operatorname{den}^{15-17}$. The S\&E is widely used to assess disability in performing $A D L$ in people with PD. It uses a percentage scale divided into deciles, with $100 \%$ representing completely normal and independent functioning and $0 \%$ representing total helplessness ${ }^{15-17}$.

The Brazilian version of the BBS was used to measure balance abilities ${ }^{18}$ and was completed by two other examiners who received identical training. BBS consists of 14 items that evaluate balance abilities during tasks involving sitting, standing and changing position. Scoring is based on the individual's ability to perform each task independently and/or meet certain time or distance requirements. The scale consists of 14 tasks common in everyday life. The items test the subject's ability to maintain positions or movements of increasing difficulty by diminishing the base of support from sitting to standing to single leg stance. The ability to change positions is also assessed. The 14 items are, in this order: sitting to standing (B1); standing unsupported (B2); sitting with back unsupported but feet supported on the floor or on a stool (B3); standing to sitting (B4); transfer (B5); standing unsupported with eyes closed (B6); standing unsupported with feet together (B7); reaching forward with outstretched arm while standing (B8); picking up an object from the floor from a standing position (B9); turning to look behind over left and right shoulders while standing (B10); turning 360 degrees (B11); placing alternate feet on step or stool while standing unsupported (B12); standing unsupported with one foot in front (B13) and standing on one leg $(B 14)^{6,7}$.

Statistical analyses were performed with SPSS v12.0 software for Windows. Mean and standard deviation (SD) were calculated for each of the measures. Intra-class coefficient correlation (ICC) 
was calculated to evaluate inter-rater reliability and Chronbach's $\bigoplus$ was calculated to evaluate internal consistency of the total BBS score. Correlation analyses between PD-specific instruments and the BBS were calculated using Spearman's rank correlation coefficient, and such correlation indicated the criterion-related validity. The magnitude of correlation was classified according to Munro (low=0.26-0.49; moderate $=0.50-0.69$; high $=0.70-0.89$; very high $=0.90-1.00$ ) for interpretation of the correlation coefficients ${ }^{19}$. Statistical significance was set at $\mathrm{p}<0.05$.

\section{RESULTS}

The study sample was composed of 53 patients, including 16 (30.2\%) women and 37 (69.8\%) men. Severity of disease according to the UPDRS was moderate in most participants (Table 1). Patient distribution on the HY scale generally showed mild-to-moderate disease involvement: stage 1, 3 patients (5.7\%); stage 1.5, 3 patients (5.7\%); stage 2,15 patients ( $28.3 \%$ ); stage $2.5,17$ patients ( $32 \%$ ) and stage 3,15 patients $(28.3 \%)$. Percentile ratings on the S\&E likewise suggested the relatively high and generally independent functioning of the patients: rating of $100 \%, 2$ patients (3.8\%); rating of $90 \%, 18$ patients $(33.9 \%)$, rating of $80 \%, 17$ patients (32.1\%); rating of $70 \%, 14$ patients (26.4\%); rating of $60 \%$ and $50 \%, 1$ patient $(1.9 \%)$.

Regarding the psychometric properties of the BBS, the scale showed high inter-rater reliability $(I C C=0.84)$ and internal consistency (Cronbach's $\alpha=0.92$ ). There was a statistically significant negative correlation between the BBS and disease duration, ADL and motor examination subscales of the UPDRS and stages of disease when assessed by the HY. There was a statistically significant positive correlation between the BBS and the worst level of functional independence evidenced by the S\&E (Table 2). There were statistically significant correlations among all 14 items of the BBS (Table 3). The magnitude of the correlation between individual BBS items was moderate.
Table 1. Demographic and clinical features of 53 patients with Parkinson's disease (PD).

\begin{tabular}{lc}
\hline Variables & $N(\%)$ or Mean \pm SD (range) \\
\hline Gender (male/female) & $37(69.8 \%) / 16(30.2 \%)$ \\
Age (years) & $62.0 \pm 7.9(46-82)$ \\
Age of PD onset (years) & $54.6 \pm 8.6(40-77)$ \\
Disease duration (years) & $7.8 \pm 4.4(2-20)$ \\
MMSE & $25.1 \pm 3.3(18-30)$ \\
UPDRS & $41.6 \pm 17.8(12-91)$ \\
UPDRS I & $3.2 \pm 2.4(0-10)$ \\
UPDRS II & $14.8 \pm 6.9(3-27)$ \\
UPDRS III & $31.3 \pm 11.8(9-54)$ \\
HY* & $2.5(1-3)$ \\
S\&E* & $80 \%(50-100 \%)$ \\
BBS & $47.2 \pm 8.2(27-56)$ \\
\hline
\end{tabular}

*Median (range). SD: standard deviation; MMSE: Mini-Mental State Examination; UPDRS: Unified Parkinson's Disease Rating Scale; HY: HoehnYahr Staging Scale; S\&E: Schwab and England Activities of Daily Living Scale; BBS: Berg Balance Scale.

Exploratory factorial analysis using the principal components method found that two factors accounted for $64.6 \%$ of total variance of the BBS. Factor 1 was responsible for $37.1 \%$ of total variation and factor 2 was responsible for $27.4 \%$ of total variation. Table 4 shows the factorial loads for each question for two factors from the BBS.

\section{DISCUSSION}

Despite the BBS not being specific to PD, this instrument has been a valid tool for screening and assessing PD patients ${ }^{12}$. Landers et al. suggested that the BBS is most effective at discriminating PD fallers from non-fallers ${ }^{20}$.

Our results showed higher inter-rater reliability and internal consistency of the BBS in PD patients. Only two

Table 2. Spearman's rank correlation coefficient $\left(r_{s}\right)$ and $p$-value between demographic, clinical variables, and BBS; and classification of Munro for the magnitude of the correlations ${ }^{18}$.

\begin{tabular}{lccc}
\hline & \multicolumn{3}{c}{ BBS } \\
\cline { 2 - 4 } Variables & $\mathrm{r}_{\mathrm{s}}$ & $\mathrm{p}$-Value & Classification \\
\hline Age (years) & -0.016 & 0.911 & No correlation \\
Age of PD onset (years) & 0.193 & 0.171 & No correlation \\
Disease duration (years) & -0.520 & $<0.001$ & Moderate \\
UPDRS & -0.067 & 0.635 & No correlation \\
UPDRS I & -0.190 & 0.261 & No correlation \\
UPDRS II & -0.467 & 0.011 & Low correlation \\
UPDRS III & -0.374 & 0.046 & Low correlation \\
HY & -0.507 & $<0.001$ & Moderate correlation \\
S\&E & 0.492 & $<0.001$ & Low correlation \\
\hline
\end{tabular}

PD: Parkinson disease; UPDRS: Unified Parkinson's Disease Rating Scale; HY: Hoehn-Yahr Staging Scale; S\&E: Schwab and England Activities of Daily Living Scale; BBS: Berg Balance Scale. 
Table 3. Spearman's rank correlation coefficient $\left(r_{s}\right)$ and p-value between BBS items.

\begin{tabular}{|c|c|c|c|c|c|c|c|c|c|c|c|c|c|c|}
\hline & B1 & B2 & B3 & B4 & B5 & B6 & B7 & B8 & B9 & B10 & B11 & B12 & B13 & B14 \\
\hline \multirow[t]{2}{*}{ B2 } & .582 & & & & & & & & & & & & & \\
\hline & $<0.001$ & & & & & & & & & & & & & \\
\hline \multirow[t]{2}{*}{ B3 } & .351 & .807 & & & & & & & & & & & & \\
\hline & 0.009 & $<0.001$ & & & & & & & & & & & & \\
\hline \multirow[t]{2}{*}{ B4 } & .648 & .622 & .465 & & & & & & & & & & & \\
\hline & $<0.001$ & $<0.001$ & $<0.001$ & & & & & & & & & & & \\
\hline \multirow[t]{2}{*}{ B5 } & .580 & .689 & .620 & .657 & & & & & & & & & & \\
\hline & $<0.001$ & $<0.001$ & $<0.001$ & $<0.001$ & & & & & & & & & & \\
\hline \multirow[t]{2}{*}{ B6 } & .561 & .829 & .785 & .566 & .639 & & & & & & & & & \\
\hline & $<0.001$ & $<0.001$ & $<0.001$ & $<0.001$ & $<0.001$ & & & & & & & & & \\
\hline \multirow[t]{2}{*}{ B7 } & .574 & .875 & .798 & .582 & .662 & .986 & & & & & & & & \\
\hline & $<0.001$ & $<0.001$ & $<0.001$ & $<0.001$ & $<0.001$ & $<0.001$ & & & & & & & & \\
\hline \multirow[t]{2}{*}{ B8 } & .456 & .339 & .285 & .573 & .453 & .376 & .389 & & & & & & & \\
\hline & $<0.001$ & .011 & .035 & $<0.001$ & .001 & .005 & .003 & & & & & & & \\
\hline \multirow[t]{2}{*}{ B9 } & .582 & .782 & .713 & .505 & .643 & .901 & .910 & .398 & & & & & & \\
\hline & $<0.001$ & $<0.001$ & $<0.001$ & $<0.001$ & $<0.001$ & $<0.001$ & $<0.001$ & .003 & & & & & & \\
\hline \multirow[t]{2}{*}{ B10 } & .274 & .281 & .256 & .260 & .256 & .333 & .351 & .114 & .320 & & & & & \\
\hline & .043 & .037 & .060 & .055 & .059 & .013 & .009 & .406 & .017 & & & & & \\
\hline \multirow[t]{2}{*}{ B11 } & .322 & .436 & .366 & .524 & .434 & .475 & .481 & .393 & .465 & .163 & & & & \\
\hline & .017 & .001 & .006 & $<0.001$ & .001 & $<0.001$ & $<0.001$ & .003 & $<0.001$ & .233 & & & & \\
\hline \multirow[t]{2}{*}{ B12 } & .563 & .616 & .513 & .488 & .683 & .690 & .695 & .406 & .690 & .370 & .451 & & & \\
\hline & $<0.001$ & $<0.001$ & $<0.001$ & $<0.001$ & $<0.001$ & $<0.001$ & $<0.001$ & .002 & $<0.001$ & .005 & $<0.001$ & & & \\
\hline \multirow[t]{2}{*}{ B13 } & .502 & .641 & .574 & .674 & .609 & .671 & .673 & .549 & .574 & .238 & .558 & .481 & & \\
\hline & $<0.001$ & $<0.001$ & $<0.001$ & $<0.001$ & $<0.001$ & $<0.001$ & $<0.001$ & $<0.001$ & $<0.001$ & .080 & $<0.001$ & $<0.001$ & & \\
\hline \multirow[t]{2}{*}{ B14 } & .310 & .504 & .416 & .487 & .548 & .622 & .610 & .375 & .530 & .218 & .563 & .601 & .613 & \\
\hline & .021 & $<0.001$ & .002 & $<0.001$ & $<0.001$ & $<0.001$ & $<0.001$ & .005 & $<0.001$ & .110 & $<0.001$ & $<0.001$ & $<0.001$ & \\
\hline
\end{tabular}

Table 4. Factorials loads for each item in two factors extracted from BBS by varimax rotation.

\begin{tabular}{llc}
\hline & \multicolumn{1}{c}{ Factor } \\
\hline Item description of the BBS & 1 & 2 \\
\hline B7 - Standing unsupported with feet together & .896 & .274 \\
B9 - Pick up object from the floor from a standing position & .860 & .235 \\
B6 - Standing unsupported with eyes closed & .849 & .294 \\
B2 - Standing unsupported & .834 & .350 \\
B3 - Sitting with back unsupported but feet supported on floor or on a stool & .256 \\
B12 - Place alternate foot on step or stool while standing unsupported & .773 & .552 \\
B10 - Turning to look behind over left and right shoulders while standing & .697 & .130 \\
B4 - Standing to sitting & .426 & .817 \\
B13 - Standing unsupported with one foot in front & .087 & .699 \\
B8 - Reaching forward with outstretched arm while standing & .523 \\
B5 - Transfers & .151 & .681 \\
B11 - Turning 360 degrees & .498 \\
B14 - Standing on one leg & .263 & .669 \\
B1 - Sitting to standing & .442 & .668 \\
\hline
\end{tabular}


studies have assessed the clinimetric properties of the BBS in patients with idiopathic $\mathrm{PD}^{12,13}$. Qutubuddin et al. measured the criterion-related validity of the BBS in 38 men, correlating the BBS with PD-specific instruments ${ }^{12}$. Franchignoni et al. assessed 57 patients with PD, calculated Cronbrach's $\alpha$ and correlated the BBS with instruments used in $\mathrm{PD}^{13}$. Internal consistency in that study was also high ${ }^{13}$.

Our results showed that balance performance was negatively affected by longer duration of disease, severity of symptoms and greater impairment on subscales II and III of the UPDRS, advanced stage of disease when assessed by $\mathrm{HY}$ stages and worst level of functional independence evidenced by the S\&E. This is in line with previous works that have demonstrated similar findings in PD patients, but only Franchignoni et al have showed correlation between the BBS and the subscale II of the UPDRS ${ }^{10,12,21}$. As PD progresses, significant changes in posture and predisposition to fall may develop. This predisposition to fall may induce psychological reactions characterized by fear of future falling ${ }^{5,22}$. This fear of falling can be maladaptive when it compels patients to restrict their mobility, independence and social participation, leading to further limitation and gradual physical disability.

As seen in Table 4, items directly related to static balance (items B2, B3, B6, B7, B9, B10, B12) belonged to factor 1 . The items related to dynamic balance $(B 1, B 4, B 5, B 8$, $B 11, B 13, B 14)$ had the highest load factor in factor 2 . These items require major postural adjustments, both anticipatory and continuous, when compared to items of component 1. Both factors accounted for a great percentage of total variance of the BBS and their items were grouped in a logical way. However some minor inconsistencies should be noticed. Item B3 showed ceiling effect in $83 \%$ of patients. Many patients (52\%) in item B11 were able to turn to both sides safely, but slowly, which may have been influenced mainly by bradykinesia, not by the lack of balance. Item B12 also loaded on factor 2, but less significantly. Accordingly, Franchignoni et al. suggested that some items on this scale should be revised to improve its validity in PD patients.

In conclusion, the instrument seemed to be suitable for the assessment of PD patients. BBS correlated with the severity of symptoms, the stage of disease and the level of independence. Studies evaluating the effect of pharmacological treatments and/or rehabilitation techniques on PD should use BBS.

\section{REFERENCES}

1. Lau LM, Breteler MM. Epidemiology of Parkinson's disease. Lancet Neurol 2006;5:525-535.

2. Samii A, Nutt JG, Ransom BR. Parkinson's disease. Lancet 2004;363: 1783-1793.

3. Calne D. A definition of Parkinson's disease. Parkinsonism Relat Disord 2005;11:39-40

4. Bloem BR, Grimbergen YA, Cramer M, Willemsen MD, Zwinderman AH. Prospective assessment of falls in Parkinson's disease. J Neurol 2001;248:950-958.

5. Franchignoni F, Martignoni E, Ferriero G, Pasetti C. Balance and fear of falling in Parkinson's disease. Parkinsonism Relat Disord 2005;11:427-433.

6. Berg KO, Wood-Dauphinée SL, Williams JI, Maki B. Measuring balance in the elderly: validation of an instrument. Can J Public Health 1992; 83(Suppl):S7-S11.

7. Berg KO, Maki BE, Williams JL, Holliday PJ, Wood-Dauphine SL. Clinical and laboratory measures of postural balance in an elderly population. Arch Phys Med Rehabil 1992;73:1073-1080.

8. Mao HF, Hsueh IP, Tang PF, Sheu CF, Hsieh CL. Analysis and comparison of the psychometric properties of three balance measures for stroke patients. Stroke 2002;33:1022-1027.

9. Stevenson TJ. Detecting change in patients with stroke using the Berg Balance Scale. Aust J Physiother 2001;47:29-38.

10. Steffen T, Seney M. Test-retest reliability and minimal detectable change on balance and ambulation tests, the 36-Item Short-Form Health Survey, and the Unified Parkinson Disease Rating Scale in people with Parkinsonism. Phys Ther 2008;88:733-746.

11. Nova IC, Perracini MR, Ferraz HB. Levodopa effect upon functional balance of Parkinson's disease patients. Parkinsonism Relat Disord 2004;10:411-415

12. Qutubuddin AA, Pegg PO, Cifu DX, Brown R, McNamee S, Carne W. Validating the Berg Balance Scale for patients with Parkinson's disease: a key to rehabilitation evaluation. Arch Phys Med Rehabil 2005;86:789-792.

13. Franchignoni F, Maugeri FS, Velozo CA. Use of the Berg Balance Scale in Rehabilitation Evaluation of patients with Parkinson's disease. Letters to the editor. Arch Phys Med Rehabil 2005;86:2225-2226.

14. Brucki SMD. Sugestões para o uso do Mini-Exame do Estado Mental no Brasil. Arq Neuropsiquiatr 2003;61:777-781.

15. Fahn S, Elton R. Unified Parkinson's Disease Rating Scale. In: Fahn S, Marsden CD, Caine DB, Goldstein M (Eds). Recent developments in Parkinson's disease. Vol. 2. Florham Park: Macmillan Health Care information 1987;153-63,293-304.

16. Hoehn MM, Yahr MD. Parkinsonism: onset, progression and mortality. Neurol 1967;17:427-442.

17. Goulart F, Pereira LX. Uso de escalas para avaliação da doença de Parkinson em fisioterapia. Fisioterapia e Pesquisa 2005;11:49-56.

18. Miyamoto ST, Lombardi IJ, Berg KO, Ramos LR, Natour J. Brazilian version of the Berg Balance Scale. Braz J Med Biol Res 2004;37:1411-1421.

19. Munro BH. Statistical methods for health care research. $4^{\text {th }}$ Ed. Philadelphia: Lippincott/Raven Publishers, 2001:223-243.

20. Landers MR, Backlund A, Davenport J, Fortune J, Schuerman S, Altenburger P. Postural instability in idiopathic Parkinson's disease: discriminating fallers from nonfallers based on standardized clinical measures. J Neurol Phys Ther 2008;32:56-61.

21. Brusse KJ, Zimdars S, Zalewski KR, Steffen TM. Testing functional performance in people with Parkinson disease. Phys Ther 2005;85:134-141.

22. Wood BH, Bilclough JA, Bowron A, Walker RW. Incidence and prediction of falls in Parkinson's disease: a prospective, multi-center study. J Neurol Neurosurg Psychiatry 2002;72:721-725. 